Fragaszy, D. M., Visalberghi, E., \& Galloway, A. T. (1997). Infant tufted capuchin monkeys' behaviour with novel foods: Opportunism, not selectivity. Animal Behaviour, 53(6): 1337-1343. (June 1997) Published by Elsevier (ISSN: 1095-8282).

\title{
Infant tufted capuchin monkeys' behaviour with novel foods: opportunism, not selectivity
}

\author{
D. Fragaszy, E. Visalberghi, and A. Galloway
}

\begin{abstract}
To determine whether young capuchin monkeys, Cebus apella, selectively interacted with others concerning novel foods, 11 infants (4.5-12 months) living in two groups were observed following presentation of familiar or novel foods. Foods were presented either to the whole group or to infants in a section of the home cage to which only they had access. Infants showed more frequent interest in others' food and picked up foods more frequently when foods were novel, and they tended to eat novel foods more frequently than familiar foods. The pattern was the same whether the foods were presented to the group or only to infants. Infants expressed interest in others' novel foods equally often before and after sampling these foods themselves. The frequency of interest in others' food correlated positively with age. It is concluded that acceptance of novel foods in these monkeys occurs readily regardless of socially provided information about edibility. Social interactions do not appear to make important contributions to acceptance of novel foods by infant capuchin monkeys.
\end{abstract}


Social sources of information about foods are apparently important in the development of diet patterns in young rabbits and rats (Galef 1976; R. Hudson, A. Bilko \& V. Altbacker, unpublished data) and the acceptance of novel foods among older animals. Galef (1993) argued that neophobia towards foods, coupled with readier acceptance of a novel food following exposure to a conspecific that has previously eaten the food, reduce the risk of enlarging the diet for a generalist omnivore such as the rat. In this view, social facilitation of feeding ought to be more evident with novel foods than with familiar foods. Acceptance of novel foods in older juvenile and adult capuchin monkeys, Cebus apella, has been shown to fit the pattern predicted by Galef (1993). Consumption of novel foods was enhanced when individuals ate with others compared to when they encountered the foods while alone, but social context did not affect consumption of familiar foods (Visalberghi \& Fragaszy 1995).

There are many striking images and reports from field settings of primate infants examining and sampling others' food, and a few reports document the frequency of such interactions (e.g. King 1994). A general assumption is that an infant primate's experiences with foods while near the mother or other kin, in particular, and social partners in general, have a formative role in its selection of foods later on (e.g. Fedigan 1982; Box 1984; Watts 1985). The linked assumptions that infants are learning something from these interactions, however, and that they engage in them for this purpose, warrant closer scrutiny (e.g. Milton 1993). First, few systematic data relate infants' interactions with others during feeding to their subsequent feeding behaviour. Second, one cannot know whether the foods so examined are novel to the infant, and so one cannot conclude that infants learn that some new item is edible from interacting with others (King 1994). Finally, we do not know whether infants engage in these interactions selectively, in a manner conducive to learning from more knowledgeable others, or merely do so opportunistically with any individual holding an item of interest. The process could occur randomly, uninfluenced by the young animal's competence at feeding itself or what was being eaten, or young animals could selectively approach others with unfamiliar items or items 
that it has difficulty obtaining itself (King 1994). King argued from field data that young savannah baboons, Papio cynocephalus, selectively approach and interact with adults feeding upon favoured and difficult foods, and that these actions might benefit infants' current and future foraging success. As she notes, however, her field data are not sufficient to make a strong test of the hypotheses. We took up some of these issues in a study of infant capuchin monkeys in captivity.

In captivity, transfers between capuchin monkeys of food as well as other objects of interest, particularly between others and infants, are commonplace and occur in an atmosphere of tolerance (Westergaard \& Fragaszy 1985; Fragaszy \& Visalberghi 1989; de Waal et al. 1993; Furbush 1994). If the foods obtained through interactions with others were novel, young individuals could learn about the acceptability of foods from others in their group through food-related interactions and socially mediated transfers of food. But do they engage in these activities selectively to learn about novel foods? Is acceptance of a novel food dependent upon, or enhanced by, these kinds of interactions?

In this study, we investigated whether young capuchin monkeys show selectivity in feeding and in inspecting others' novel foods, in line with King's (1994) model of the active role of infants in acquiring information about foods drawn from her observations of baboons. We expected that young capuchin monkeys would show some avoidance of novel foods. We also expected that infant capuchins would show more interest in others' food when encountering a novel food than a familiar food (as captive capuchin monkeys do with other novel items; e.g. Visalberghi 1988). Furthermore, and relevant to King's model, if infants seek information from adults about acceptability of a potential food, infants should (1) seek information from others about novel foods, through approach and interaction with food holders, more often before than after first eating them, and (2) eat fewer novel foods, or eat them later, when the foods are available only to infants than when they are available to all members of the group. Finally, we considered the relation between age of the infant and extent of interest in others' food. Older infants, 
approaching weaning and partially responsible for feeding themselves, could be expected to have greater interest in others' food than younger infants, if interest is related to the functional problem of knowing whether something is edible. If no relation between age and interest exists, then interest is not likely to be related to youngsters' growing self-reliance in feeding.

\section{METHODS}

\section{Design}

We presented subjects with two kinds of foods (Familiar or Novel) in two conditions (Group or Box). In the Group condition, we presented food to the whole group on the floor of the home cage. In the Box condition, foods were presented in a box, mounted on an interior wall of the home cage; up to four infants could be in the box at one time. We gave each Novel food once to each group, with assignment to Condition balanced across groups. We presented familiar foods repeatedly in both conditions.

\section{Subjects}

Subjects were 11 capuchin monkeys (six females and five males), 4.5-12 months of age at the start of testing. These infants were housed with their mothers and other group members in two groups composed of 20 and 26 individuals. All subjects lived with their mothers in their natal group. Both groups were housed indoors in two-room enclosures $(2.2 \times 4.9 \times 2.8 \mathrm{~m})$. The rooms were joined by an opaque sliding window set in a solid wall. The sliding window allowed the experimenter to keep all individuals of a group in one room while setting up the apparatus or food on the other side, out of sight of the subjects. Observations were made through a glass window at one end of the enclosure.

\section{Apparatus}

A stainless steel mesh box $(71 \times 25 \times 50 \mathrm{~cm})$ with glass front facing the observer's window was used to contain food in the Box condition. Subjects 
entered the box on one side through a sliding panel door closed down to a 5-cm width. A small container $(10 \times 10 \times 5 \mathrm{~cm})$, mounted on the floor of the box at the wall opposite the opening, held the food. Only individuals inside the box could take food from the container. The box was mounted along the back wall of the cage, near perches, which made it easily accessible. We left the apparatus mounted with doors open wide for several days before testing began. This habituated subjects to the point where all individuals entered the box freely, and it quickly became a preferred sitting place.

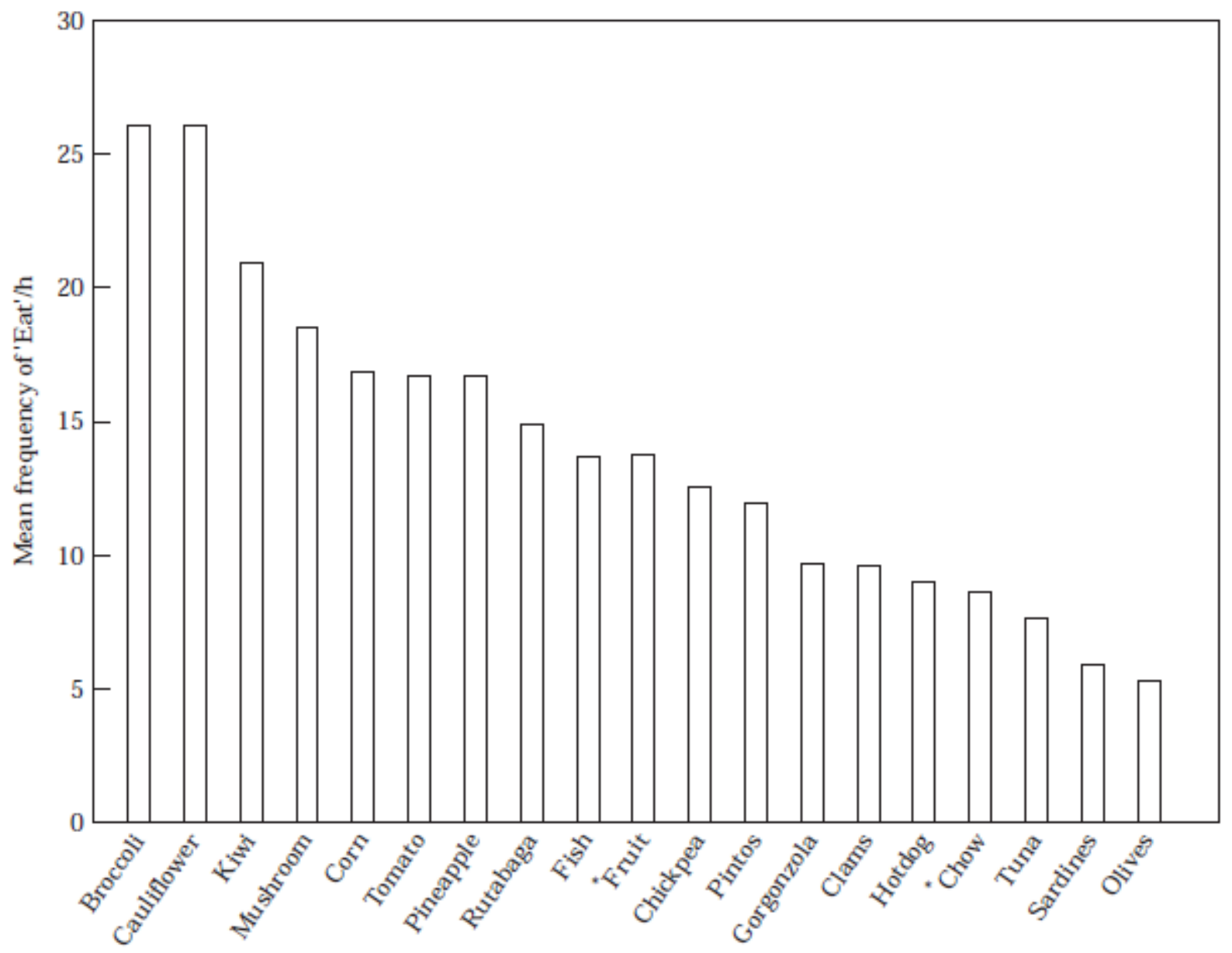

Figure 1. Rate at which subjects ate novel and familiar foods $\left(^{*}\right)$.

We presented subjects with 17 Novel or two Familiar foods (Fig. 1). All foods were divided into $2 \times 2 \times 2-\mathrm{cm}$ cubes for presentation. The familiar foods were experienced daily by both 
groups, before and during the study. The novel foods had not been eaten previously by any group member. The novel foods were selected to provide a diverse array of unprocessed or minimally processed food types.

\section{Procedure}

Testing began in mid-afternoon, several hours after the morning feeding. On one day we tested both groups with the same food, each group in a different condition (Box or Group). We presented 8 ounces of food (Box condition), or 32 ounces of food on a cleared area of the floor (Group condition). The food was placed in the appropriate area while all the monkeys were locked in the adjoining room. The two observers began collecting data by keyboard when the sliding window of the observation room was opened. The monkeys entered the testing area as soon as the window opened.

Focal subjects were sampled during 10-min observation periods, and three 10-min periods constituted one observation session. Two observers collected data during each period, so that between them, all the subjects in one group could be sampled once during each session. Between observation periods, we refreshed the food supply. Data collection occurred from April to June 1994.

Activities of the focal animal were recorded on a continuous basis using the Observer software package (Noldus Information Technology, Inc. Wageningen, The Netherlands). Food-related behaviours were categorized as: (a) Interest, (b) Picks up food and (c) Eats food. The Interest category included any interaction with other individuals that could give the subject information about the food. These interactions included (1) peering at another individual at close range (within arm's reach), (2) attempting to take food from another individual and touching the food in the process, (3) reaching for another's food without touching it, (4) sniffing another's mouth and (5) taking food from other individuals. The Pick up food category required that the subject pick up the food from an inanimate surface in one or both hands. If the 
subject put food in its mouth, it was labelled Eat. A new bout of eating was scored only after the previous piece of food had been consumed or abandoned. Latency to first consumption was noted.

Inter-observer reliability was $100 \%$ for subject identifications and over $90 \%$ for behaviour identifications. Inter-observer reliabilities were calculated for four sessions as the sum of agreements between observers divided by the sum of the agreements and disagreements between observers. Reliability was checked before data collection began.

\section{Analysis}

Frequency data were tabulated per subject/ session, and per food over all sessions. The number of subjects eating a food at least once was tallied. Non-parametric statistics were used for variables with many zero values or other deviations from normal distribution; otherwise, the parametric $t$-test was used where appropriate. Two-tailed values of alpha were used to determine statistical significance, with $P<0.05$ set for statistical significance. After determining that individual scores were consistent between sexes and groups, we pooled subjects into one population for all analyses.

\section{RESULTS}

\section{Acceptance of Novel Foods}

Every novel food was eaten by five or more infants $(X=8.0)$, and each infant ate eight or more novel foods $(X=12.2)$. Eating occurred in $75 \%$ of sessions with novel foods and $73 \%$ of sessions with familiar foods. Some infants ate more than others: There was a moderate positive correlation between the frequency of eating novel foods and eating familiar foods ( $r S=0.62, N=11, P<0.05$, one-tailed). There was no correlation between age and the frequency of eating all foods, however ( $r S=" 0.08, N=11, N S$ ), or novel foods $(r S=" 0.05, N=11, N S)$. Average latencies to pick 
up foods were similar for familiar and novel foods: 84-94 s in Group sessions, and 114-139 s in Box sessions, respectively. Latency to first consumption was also similar for novel and familiar foods in both conditions. Consumption typically occurred within seconds of picking up the food.

Nine of 10 infants in Group sessions, and 10 of 11 in Box sessions, picked up novel foods more frequently than familiar foods (sign test, $P<0.03$ for both). Most infants also ate novel foods more frequently than familiar foods (Box condition: 8 of 11; Group condition: 8 of 10). The bias towards greater frequency of consumption was evident for most novel foods (Fig. 1): 14 of 17 foods were eaten more frequently than chow was eaten, for example.

\section{Box versus Group Conditions}

No significant differences were present between Group and Box conditions for any variable.

\section{Factors affecting Frequency of Interest}

Interest in others' food occurred, on average, 13.5 times in each subject across all sessions (range=5-28). Older infants were more likely to show interest in others' food than were younger infants: frequency of interest in others' food was significantly positively correlated with age ( $r \mathrm{~S}=0.70, N=11, P<0.05)$.

Nine of 11 subjects in the Group sessions, and 8 of 9 in the Box sessions, expressed more frequent Interest in Novel than Familiar foods (sign test; Group: $P=0.066$, Box: $P=0.004$ ). For example, the average frequency per session in Group sessions was 0.96 for novel food versus 0.49 for familiar food. 

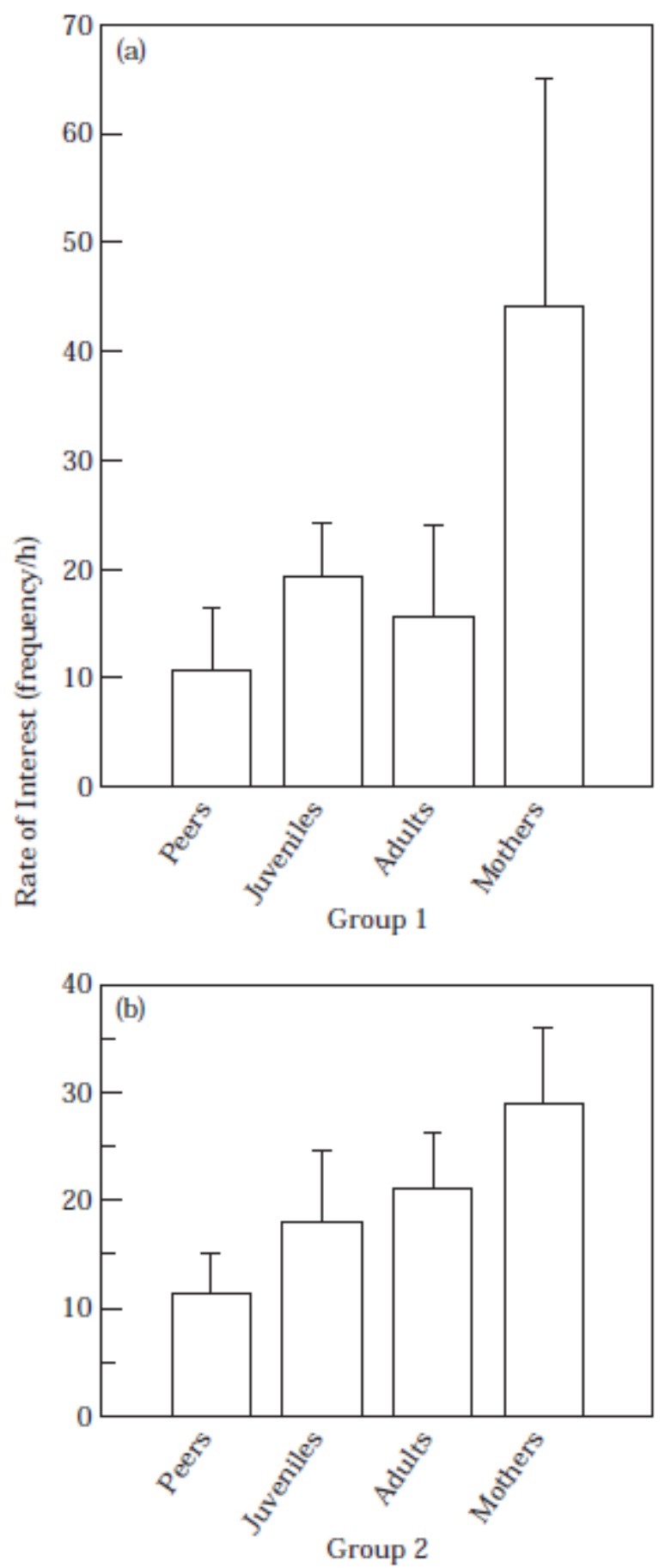

Figure 2. Mean+SE frequency of Interest to social partners in (a) group 1 and (b) group 2.

Nearly all group members were approached by infants when they held food, including unrelated adults of both sexes and other infants (Fig. 2). 
The infants' mothers were the most popular, receiving $17 \%$ of infants' interest (whereas they constituted only $4-5 \%$ of possible targets of interest), although two of 11 infants never approached their mothers. Four of the infants approached their mothers 4-10 times more often than expected by chance. Two of these infants were the oldest; two were among the three youngest. Thus no uniform relationship exists between selective approaches to the mother and age, although overall interest was significantly correlated with age. There was also no relationship between age and extent of selectivity towards approaching adults ( $\$ 5$ years) other than the mother ( $r S=" 0.02, N=11, N S)$. Overall, infants directed Interest towards adults other than the mother about as often as towards other infants or juveniles (dependent $t 10=0.94, N S$ ).

\section{Infants do not Selectively Express Interest Before Eating}

If infants seek information about foods from others to resolve a current uncertainty, they should express interest before rather than after eating. This was not the case. In the Novel condition, of all sessions in which a subject ate, the subject expressed interest before eating in 24\% of sessions, after eating in $25 \%$ of sessions and no interest in $51 \%$ of sessions. Thus, no bias exists towards expressing interest prior to eating a novel food. For familiar foods, no interest was expressed on $77 \%$ of sessions in which eating occurred. Interest followed eating in $17 \%$ of sessions and preceded eating in $6 \%$ of sessions. These results indicate that, although infants were more likely to display interest when a novel food was presented than when a familiar food was presented, their interest did not selectively occur before eating.

There was no relation between the frequency of consumption of a food and the frequency with which interest was expressed by infants towards holders of that food ( $\mathrm{S}==0.08, N=11, \mathrm{NS})$. Similarly, the frequency with which a subject expressed Interest in another's food was uncorrelated with the frequency with which that subject ate $(r S=" 0.05, N=11, N S)$. Together with the data on the timing of interest (before or 
after eating), these findings suggest that infants opportunistically displayed interest, rather than systematically seeking information.

\section{DISCUSSION}

\section{Infants do not Avoid Novel Foods}

Contrary to our previous work with older individuals of the same species (Visalberghi \& Fragaszy 1995), and contrary to prevailing observations about reactions to novel foods in other species (Galef 1993), infant capuchin monkeys did not treat novel foods with caution. Rather, they picked up and ate novel foods more often than they did familiar foods, regardless of whether they were presented in the home cage to all animals or in a special area reserved for the infants. Infants discriminated between familiar and novel foods, however, expressing interest in another's food significantly more frequently when it was novel. Thus, infants detected the novelty of the foods, but novelty enhanced rather than diminished the probability that they would eat. We do not know whether the contrast in results between this study and our earlier study (Visalberghi \& Fragaszy 1995) indicate an age difference general to the species (i.e. infants do not show neophobia towards food; older animals do), or whether we have a group-specific difference in extent of neophobia. From an energetic point of view, however, infant and juvenile monkeys should be less neophobic towards novel foods than adults of the same species; for example juveniles are less efficient foragers and at greater risk for starvation than adults (Janson \& van Schaik 1993).

\section{Infants do not Selectively Seek Information from Adults}

Neither hypothesis relating to the possibility that infants selectively seek information about novel foods was supported. Infants expressed more frequent interest in others' novel foods than in their familiar foods, as predicted on the basis of general curiosity towards novel things. Infants expressed interest in others' food equally often before and after eating the food for the first time, 
however, and they ate novel foods as readily when they were presented away from adults as when they were presented to the whole group. In short, no evidence suggested that infants selectively sought information from particular others or about the foods before eating novel foods. Moreover, interest was uncorrelated with the frequency of eating a food.

\section{Relation between Interest and Age}

Interest in others' food was significantly correlated with age, occurring more frequently in the older infants, even though the frequency of eating a food was independent of age. Thus, interest is more evident as infants become more responsible for feeding themselves. Weaning is a gradual process in this species, occurring over several months during the second year (Fragaszy \& Adams-Curtis 1994). Our oldest subjects were just about to begin weaning, and they were responsible for an unknown but growing proportion of their own nutrition. Perhaps they had greater motivation to seek food of any kind (familiar or novel) than did the younger infants. In addition to any immediate metabolic basis for increased interest in food, however, animals in the second year of life are also simply more manipulative overall than infants in the first year (D. Fragaszy \& L. Adams-Curtis, unpublished data). Infants 13-18 months old show the highest frequencies of manual activity (with all objects and surfaces) of any age group. In short, the young capuchin monkey during weaning (12-18 months) is an active and curious individual that will frequently interact with all aspects of the environment that attract its interest. This system apparently functions without selective attention to particular others, however. Weanling capuchins in natural settings do not receive an appreciable amount of nutrition by taking food from others; they must be self-sufficient.

\section{Relevance of Social Interactions to Development}

Does the opportunistic nature of capuchins' explorations of others' foods, coupled with their ready acceptance of novel foods encountered away from others, limit the importance of social 
interactions for (1) broadening the diet of an individual or (2) producing a group-homogeneous diet (the usual functional explanations of inspecting others' foods)? It seems so. We predict that development of a group-homogeneous diet exploiting all readily available foods, and dietary change (i.e. inclusion of a new item in the diet) occurs easily among capuchins, especially young capuchins, even without social transfer of information. Social processes supporting acceptance of foods might contribute to the speed of the process, especially for older animals, which apparently are more neophobic than youngsters. Social processes might thus promote dietary flexibility in times of rapid changes in food availabilities. This hypothesis is a reversal of the usual notion that social learning processes are more important for youngsters than for adults, since adults already know what to eat.

Our findings suggest that, for captive capuchins, young monkeys are not selective seekers of information about novel foods when the foods are easy to obtain and to process. We do not know how these behaviours would differ in monkeys in other settings. Moreover, species may differ widely in this domain, as in so many other aspects of social behaviour and foraging ecology. Discerning common elements of social learning across species and settings will require further comparative study, with attention to the ecological and life-history characteristics of each species.

\section{ACKNOWLEDGMENTS}

This work was supported by a Bilateral ItalyU.S.A. grant to E.V. and D.F. from the Consiglio Nazionale delle Ricerche, Italy. We thank Devjani Mitra for help in collecting data. Thanks also to B. King and an anonymous referee for comments on an earlier version of the manuscript. 


\section{REFERENCES}

Box, H. O. 1984. Primate Behaviour and Social Ecology. London: Chapman \& Hall.

Galef, B. J. 1976. Social transmission of acquired behavior: a discussion of traditions and social learning in vertebrates. Adv. Study Behav., 6, 77-100.

Galef, B. G., Jr 1993. Function of social learning about food: a causal analysis of effects of diet novelty on preference transmission. Anim. Behav., 46, 257-265.

Fedigan, L. M. 1982. Primate Paradigms: Sex Roles and Social Bonds. Montreal: Eden Press.

Fragaszy, D. M. \& Adams-Curtis, L. E. 1994. Growth and reproduction in tufted capuchins: a ten-year retrospective of a captive colony. Am. J. Primatol., 33, 208.

Fragaszy, D. M. \& Visalberghi, E. 1989. Social influences on the acquisition of tool-using behaviors in tufted capuchin monkeys (Cebus apella). J. comp. Psychol., 103, 159-170.

Furbush, S. R. 1994. Feeding behavior in captive Cebus apella: the effects of age, sex, and kinship. Master's thesis, University of Georgia.

Janson, C. J. \& van Schaik, C. P. 1993. Ecological risk aversion in juvenile primates: slow and steady wins the race. In: Juvenile Primates. Life History, Development and Behavior (Ed. by M. E. Pereira \& L. A.

Fairbanks), pp. 57-74. New York: Oxford University Press.

King, B. J. 1994. The Information Continuum: Evolution of Social Information Transfer in Monkeys, Apes, and Hominids. Santa Fe, New Mexico: SAR Press.

Milton, K. 1993. Diet and social organization of a free-ranging spider monkey population in Panama: the development of a species-typical behaviour in the absence of adults. In: Juvenile Primates. Life History, Development and Behavior (Ed. by M. E. Pereira \& L. A. Fairbanks), pp. 173-188. New York: Oxford University Press. 
Visalberghi, E. 1988. Responsiveness to objects in two social groups of tufted capuchin monkeys (Cebus apella). Am. J. Primatol., 15, 349-360.

Visalberghi, E. \& Fragaszy, D. M. 1995. The behaviour of capuchin monkeys, Cebus apella, with novel food: the role of social context. Anim. Behav., 49, 10891095.

de Waal, F. B. M., Luttrell, L. M. \& Canfield, M. E. 1993. Preliminary data on voluntary food sharing in brown capuchin monkeys. Am. J. Primatol., 29, 73-78.

Watts, D. P. 1985. Observations on the ontogeny of feeding behavior in mountain gorillas (Gorilla gorilla beringei). Am. J. Primatol., 8, 1-10.

Westergaard, C. G. \& Fragaszy, D. M. 1985. The manufacture and use of tools by capuchin monkeys (Cebus apella). J. comp. Psychol, 101, 159-168. 